14

\title{
Влияние излучения крайне высоких частот на выработку серотонина в живом организме
}

\author{
(C) А.О. Вонти ${ }^{1}$, А.В. Ильинский ${ }^{1}$, Я.С. Кацнельсон ${ }^{2}$, \\ E.Б. Шадрин ${ }^{1, \uparrow}$ \\ ${ }^{1}$ Физико-технический институт им. А.Ф. Иоффе РАН, Санкт-Петербург, \\ Россия \\ ${ }^{2}$ Premier Annecto Technologies, Doylestown, Pennsylvania, USA \\ E-mail: shadr.solid@mail.ioffe.ru
}

Поступило в Редакцию 7 мая 2018 г.

Представлены результаты исследования влияния излучения крайне высоких частот $(54 \mathrm{GHz})$ на выработку условного рефлекса у крыс, подвергнувшихся токовому стрессу в отсутствие и в присутствии электромагнитного излучения. Обсуждаются биофизические процессы механизма такого влияния.

DOI: $10.21883 /$ PJTF.2018.17.46567.17374

В мировой литературе представлено немало экспериментального материала по проблеме влияния электрических и магнитных полей на биологические процессы, протекающие в живом организме [1,2]. Особое место в этой проблеме занимает транскраниальная электромагнитная стимуляция излучением крайне высокой частоты (КВЧ). Данный вид излучения как метод бесконтактной терапии все шире применяется в последние годы в медицинской практике и в связи с этим требует детального изучения способа его воздействия на живые организмы [3]. В настоящей работе кратко обсуждаются экспериментальные данные по влиянию КВЧ-излучения на выработку условного рефлекса (УР) у лабораторных животных (крыс), подвергнувшихся токовому стрессу в отсутствие и в присутствии КВЧ-излучения. Подробно обсуждается механизм такого влияния.

В экспериментах использовались четыре группы половозрелых крыс, в каждой группе было по 11 животных. Первая группа была контрольной: она не подвергалась стрессовому воздействию. 
Животные второй группы подвергались токовому стрессорному воздействию в течение $10 \mathrm{~min}$. Фиксировалось число сочетаний условного раздражителя (звук с частотой $50 \mathrm{~Hz}$ и громкостью $60 \mathrm{~dB}$ ) и безусловного подкрепления (подаваемых на лапки животного импульсов тока амплитудой $100 \mathrm{mV}$ и длительностью $8 \mathrm{~ms}$ ), приводящего к выработке УР, т.е. в процессе экспериментов вырабатывался УР активного избегания болевого раздражения при подаче звукового сигнала. Для животных второй группы УР возникал после шести-семи сочетаний условного и безусловного раздражителей.

Было обнаружено явление химической блокировки процесса выработки УР. Блокировка выработки УР осуществлялась для животных третьей группы с помощью излучения КВЧ. Сначала проводилось КВЧ-облучение кожных покровов черепа животного в течение 10 min непосредственно перед выработкой УР при токовом воздействии на лапки животного. Параметры КВЧ были следующими: частота $54 \mathrm{GHz}(\lambda=5.6 \mathrm{~mm})$, плотность мощности излучения $300 \mathrm{~mW} / \mathrm{cm}^{2}$, площадь облучаемой области головы животного около $2 \mathrm{~cm}^{2}$. Поток КВЧ-излучения модулировался низкочастотной последовательностью прямоугольных импульсов частотой $78 \mathrm{~Hz}$ с крутизной фронтов не более $1 \mathrm{~ms}$. Для животных третьей группы наблюдалось почти полное подавление процесса выработки УР после КВЧ-излучения в $50 \%$ случаев, частичное затормаживание процесса выработки УР после КВЧ-излучения в $25 \%$ случаев. Во всех случаях, когда имела место успешная выработка УР (75\% животных), УР сохранялся через сутки после его выработки.

Хорошо известно [4], что блокированию выработки УР способствует появление в живом организме серотонина. Блокировать же действие серотонина можно с помощью китрила. Поэтому для животных четвертой группы китрил вводился за $30 \mathrm{~min}$ до начала КВЧ-облучения, а затем КВЧ-облучение осуществлялось в течение $10 \mathrm{~min}$, так же как и для животных третьей группы. Результаты превзошли ожидания: действие КВЧ-излучения практически отсутствовало. Другими словами, в 91\% случаев какого-либо торможения выработки УР избегания болевого раздражителя не было зафиксировано, причем сохранение УР избегания в течение суток было зафиксировано в $100 \%$ случаев. Итак, можно считать доказанным, что процесс блокировки выработки УР КВЧ-излучением обусловлен выработкой серотонина в структурах

Письма в ЖТФ, 2018, том 44, вып. 17 
мозга, поскольку введение китрила до начала КВЧ-излучения исключает такую блокаду.

Таким образом, воздействие КВЧ-излучения небольшой мощности $\left(300 \mathrm{~mW} / \mathrm{cm}^{2}\right.$ в течение $\left.10 \mathrm{~min}\right)$ на здоровое животное погружает его в состояние обездвиженности, при этом снижаются реакции на внешние раздражители, частота дыхания и пульс. Кроме того, животное, подвергшееся облучению, теряет способность к выработке УР защиты от токового стрессорного воздействия. С другой стороны, с помощью наших специальных экспериментов показано, что излучение не проникает непосредственно сквозь кости черепа. Оно не способно непосредственно влиять на процессы, протекающие в мозге животного.

Возникшее противоречие исключает множество механизмов прямого (непосредственного) воздействия КВЧ-излучения на структуры мозга. Тем не менее опыт показывает, что микроволновое излучение оказывает сильное воздействие на поведение животного. Другими словами, информация о воздействии КВЧ-излучения на кожные покровы головы животного эффективно переносится в мозг, что надежно фиксируется по изменению поведения животного.

Стрессорные воздействия на организм животных в обычных условиях приводит к установлению новых связей в нейронной сети коры головного мозга. Эти связи ответственны за выработку УР и дальнейшее поведение животного. Механизм воздействия КВЧ-излучения на поведение животного, по нашему мнению, заключается, как указывалось, в выработке серотонина при КВЧ-облучении наружных кожных покровов головы животного. В случае блокады серотонинергических рецепторов с помощью китрила КВЧ-излучение уже не оказывает никакого действия, поэтому вопрос о выработке серотонина с помощью КВЧ-излучения экспериментально обоснован. Проблема, однако, заключается в том, что само электромагнитное излучение в мозг животного не проникает ввиду того, что оно полностью поглощается костями черепа. Кроме того, энергия кванта излучения КВЧ весьма мала $(0.2 \mathrm{meV})$ по сравнению с энергией тепловых флуктуаций $(k T=30 \mathrm{meV})$ и, казалось бы, не в состоянии оказать заметное действие на выработку серотонина в мозге. Тем не менее такое сильное влияние обнаружено. Для разрешения этого парадокса мы предлагаем принять во внимание возможность опосредованного воздействия КВЧизлучения на мозг животного. Для этого могут быть привлечены

Письма в ЖТФ, 2018, том 44, вып. 17 
резонансные методы воздействия электромагнитного излучения на цереброспинальную жидкость-ликвор - в кожных покровах головы животного с последующим переносом продуктов воздействия в мозг животного.

Хорошо известно [5], что серотонин $\left(\mathrm{C}_{10} \mathrm{H}_{12} \mathrm{~N}_{2} \mathrm{O}\right)$ вырабатывается нервными клетками и надпочечниками из аминокислоты - триптофана $\left(\mathrm{C}_{11} \mathrm{H}_{12} \mathrm{~N}_{2} \mathrm{O}_{2}\right)$. В природе триптофан синтезируют микроорганизмы, растения и грибы. Животные не способны синтезировать триптофан. Для животных триптофан является незаменимой аминокислотой и должен поступать в организм в достаточном количестве с белками пищи. В живом организме триптофан образует ван-дер-ваальсовы связи с альбумином, который циркулирует, в частности, в пространстве Вирхова-Робина вокруг кровеносных сосудов кожных покровов [5]. Триптофан вместе с молекулами альбумина проникает в нервную ткань и надпочечники, проходя по пространству Вирхова вдоль кровяного русла [5], в том числе и в головной мозг животного, где и вырабатывается серотонин. Таким образом, в области кожного покрова черепа серотонин отсутствует, а триптофан присутствует, будучи адгезированным к альбуминовой глобуле.

Триптофан присоединен к альбуминовой глобуле нехимическими ван-дер-ваальсовыми связями (см. рисунок) с энергией от 0.5 до $100 \mathrm{meV}$ [6], притом что тепловая энергия имеет величину $k T=30 \mathrm{meV}$. Следует подчеркнуть, что, несмотря на малость энергии связи, разрыва ван-дер-ваальсовых связей тепловыми флуктуациями не происходит [6]. В то же время энергия КВЧ-кванта, несмотря на то что она равна $0.2 \mathrm{meV}$, достаточна для того, чтобы КВЧ-облучение было способно привести к резонансному (!) разрыву ван-дер-ваальсовых связей и переводу триптофана в свободную форму.

КВЧ-излучение действует на ликвор, находящийся в пространстве Вирхова-Робина. Для доставки продуктов воздействия в мозг необходимо сохранение информации о КВЧ-воздействии на время доставки триптофана в нейронную сеть мозга для последующей генерации в ней серотонина. Роль „блока памяти“ играет при этом, по нашему мнению, сам ликвор.

Рассмотрим подробнее детали протекающих при этом биофизических процессов.

Действие КВЧ-излучения приводит к трехступенчатому конформационному переходу альбуминовой глобулы в новое клубковое состоя-

Письма в ЖТФ, 2018, том 44, вып. 17 


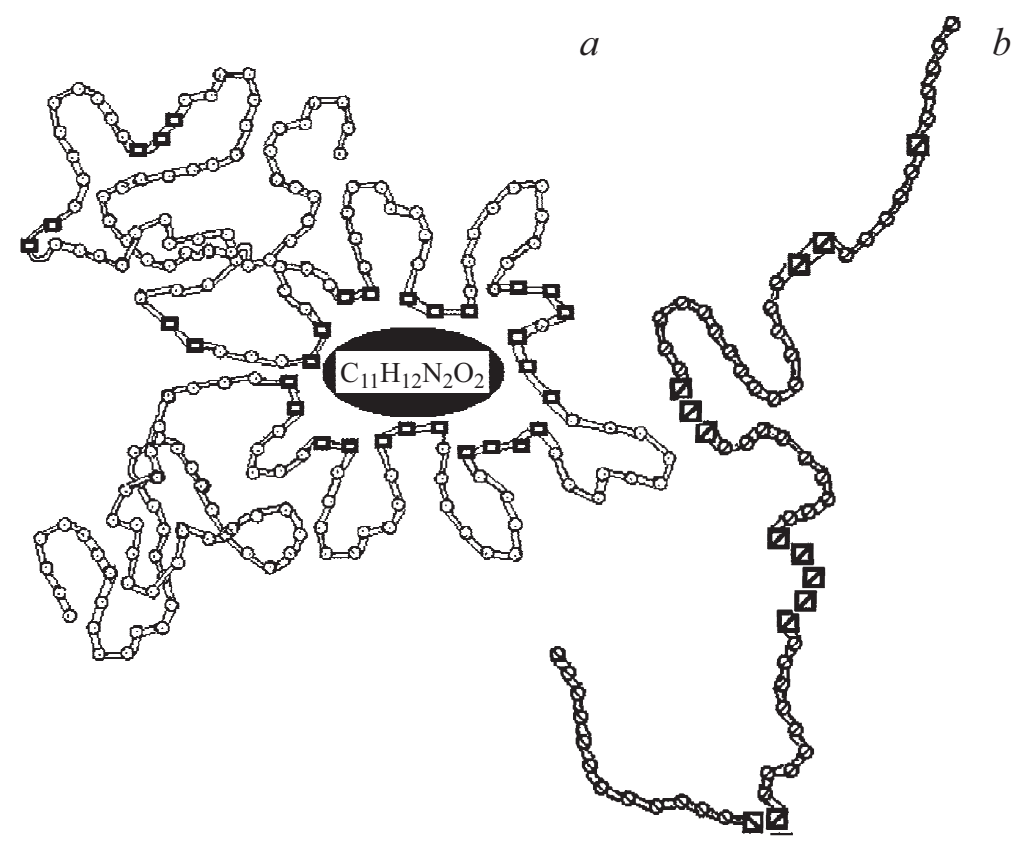

Необратимое разворачивание в клубок аминокислотной глобулярной цепи белка при фазовом переходе глобула-клубок. $a-$ фрагмент альбуминовой глобулы с активным центром, удерживающим молекулу триптофана посредством ван-дер-ваальсовых связей, $b-$ фрагмент белковой нити альбуминового клубка после фазового превращения глобулы в клубок с потерей активным центром способности удерживать триптофан.

ние. При этом альбуминовый клубок теряет способность удерживать триптофан. Такой переход экспериментально подтвержден литературными данными по двухэтапному тушению триптофановой флуоресценции сыворотки альбумина при добавлении в белковый раствор додецилсульфата натрия [7]. Результаты эксперимента указывают на трехстадийный характер денатурации: первая стадия состоит в разрыхлении белковых глобул, вторая - в полном необратимом разворачивании в клубок аминокислотной цепи белка при фазовом переходе глобула-клубок, третья - в необратимом перколяционном

Письма в ЖТФ, 2018, том 44, вып. 17 
переходе и образовании бесконечного клубкового кластера [8] с потерей способности удержания молекулы триптофана [7,9] (см. рисунок). Итак, согласно предлагаемой модели, последняя третья стадия представляет собой перколяционный фазовый переход с образованием бесконечного кластера из клубков альбумина, заключенного в гидратные оболочки [8]. Такой фазовый переход необратим [9]. Ликвор в такой стадии играет роль „элемента памяти“ и переносит теперь уже „свободный“ триптофан под кости черепа, насыщает нейронную сеть мозга, где и вырабатывается большая дополнительная доза серотонина. В конечном счете это происходит благодаря КВЧ-облучению $[10,11]$.

Резюмируя, следует отметить, что, согласно предлагаемой модели, КВЧ-облучение кожных покровов головы животного вызывает фазовый переход глобула-клубок в альбуминовых глобулах, находящихся в пространстве Вирхова-Робина, с последующим образованием бесконечного перколяционного кластера. При этом молекула триптофана становится свободной и с потоком альбумина проникает под кость черепа в нейронную сеть мозга животного. В нейронной сети мозга существенно усиливается выработка серотонина, и животное благодаря его воздействию теряет способность к выработке УР.

\section{Список литературы}

[1] Илларионов В.Е. Магнитотерапия. М: ЛИ-БРОКОМ, 2009. $136 \mathrm{c.}$

[2] Гудков А.Б., Карпин В.А., Кострюкова Н.К., Ловкина Е.С. Биологические эффекты сверхслабого магнитного поля. М: Экология человека, 2004. 592 с.

[3] Самойлов В.О., Шадрин Е.Б., Филиппова Е.Б., Каџңельсон Я.С., Бэкхов Х., Эвентов М. // Биофизика. 2015. Т. 60. В. 2. С. 377-384.

[4] Физиология человека / Под ред. В.М. Покровского, Г.Ф. Коротько. М.: Медицина, 1997. Т. 2. 368 с.

[5] Brinker T., Stopa E., Morrison J., Klinge P. // Fluids Barriers CNS 2014. V. 11. P. 10. DOI: $10.1186 / 2045-8118-11-10$

[6] Давыдов А.С. Биология и квантовая механика. Киев: Наук. думка, 1979. $296 \mathrm{c}$.

[7] Bito R., Shikano T., Kawabata H. // Biochim. Biophys. Acta. 2003. V. 1646. P. 100-111.

[8] Вонти А.О., Ильинский А.В., Капралова В.М., Шадрин Е.Б. // ЖТФ. 2018. T. 88. B. 6. C. 934-942. 
[9] Dobretsov G.E., Kurek N.K., Syrejshchikova T.I., Yakimenko M.N., Clarke D.T., Jones G.R., Munro I.H. // Nucl. Instrum. Phys. Res. A. 2000. V. 448. P. 471-477.

[10] Young S.N. // J. Psychiatry Neurosci. 2007. V. 32. N 6. P. 394-9.

[11] Isbister G.K., Bowe S.J., Dawson A., Whyte I.M. // J. Toxicol. Clin. Toxicol. V. 42. N 3. P. 277-285. DOI: $10.1081 /$ CLT-120037428

3 Письма в ЖТФ, 2018, том 44, вып. 17 